\title{
Deprivation of dietary fiber in specific-pathogen-free mice promotes susceptibility to the intestinal mucosal pathogen Citrobacter rodentium
}

\author{
Mareike Neumann ${ }^{\mathrm{a}, \mathrm{b}}$, Alex Steimle ${ }^{\mathrm{a}}$, Erica T. Grant ${ }^{\mathrm{a}, \mathrm{b}}$, Mathis Wolter ${ }^{\mathrm{a}, \mathrm{b}}$, Amy Parrish $^{\mathrm{a}, \mathrm{b}}$, Stéphanie Willieme ${ }^{\mathrm{a}}$, \\ Dirk Brenner ${ }^{\mathrm{a}, \mathrm{c}, \mathrm{d}}$, Eric C. Martens ${ }^{\mathrm{e}}$, and Mahesh S. Desai (ID) ${ }^{\mathrm{a}, \mathrm{c}}$

\begin{abstract}
aDepartment of Infection and Immunity, Luxembourg Institute of Health, Esch-sur-Alzette, Luxembourg; ${ }^{b}$ Faculty of Science, Technology and Medicine, University of Luxembourg, Esch-sur-Alzette, Luxembourg; 'Odense Research Center for Anaphylaxis, Department of Dermatology

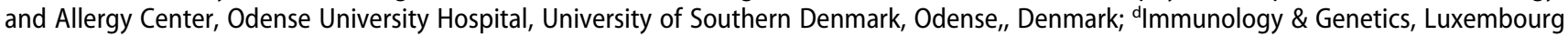
Centre for System Biomedicine (Lcsb), University of Luxembourg, Belval, Luxembourg; eDepartment of Microbiology and Immunology,
\end{abstract} \\ University of Michigan Medical School, Ann Arbor, Michigan, USA
}

\section{ABSTRACT}

The change of dietary habits in Western societies, including reduced consumption of fiber, is linked to alterations in gut microbial ecology. Nevertheless, mechanistic connections between dietinduced microbiota changes that affect colonization resistance and enteric pathogen susceptibility are still emerging. We sought to investigate how a diet devoid of soluble plant fibers impacts the structure and function of a conventional gut microbiota in specific-pathogen-free (SPF) mice and how such changes alter susceptibility to a rodent enteric pathogen. We show that absence of dietary fiber intake leads to shifts in the abundances of specific taxa, microbiome-mediated erosion of the colonic mucus barrier, a reduction of intestinal barrier-promoting short-chain fatty acids, and increases in markers of mucosal barrier integrity disruption. Importantly, our results highlight that these low-fiber diet-induced changes in the gut microbial ecology collectively contribute to a lethal colitis by the mucosal pathogen Citrobacter rodentium, which is used as a mouse model for enteropathogenic and enterohemorrhagic Escherichia coli (EPEC and EHEC, respectively). Our study indicates that modern, low-fiber Western-style diets might make individuals more prone to infection by enteric pathogens via the disruption of mucosal barrier integrity by diet-driven changes in the gut microbiota, illustrating possible implications for EPEC and EHEC infections.

\section{ARTICLE HISTORY}

Received 2 June 2021

Revised 29 July 2021

Accepted 3 August 2021

\section{KEYWORDS}

Microbiome; mucin; mucus layer; citrobacter rodentium; dietary fiber; SPF mice

\section{Introduction}

Typical diets in Western societies are characterized by a fiber intake below the recommended amount of 28-38 g per day. ${ }^{1}$ Such a reduced consumption of fiber is a possible explanation for the imbalances in gut microbial communities, which have been associated with various diseases such as inflammatory bowel disease (IBD) and colorectal cancer. ${ }^{2}$ Furthermore, several studies have shown a link between Western-style diets (WSD) and enteric pathogenic infections in mice. ${ }^{3-5}$ Specifically, bacterial metabolites derived from dietary fiber fermentation are known to impact disease severity of enteropathogenic infections. ${ }^{6}$ As shown in mouse models, apart from maintaining immune homeostasis by producing certain metabolites like shortchain fatty acids (SCFAs) from dietary fiber digestion, ${ }^{7,8}$ the intestinal microbiome confers colonization resistance against invading enteric pathogens by enhancing mucosal barrier integrity ${ }^{9}$ or by competing for the same nutritional resources. ${ }^{10}$ However, knowledge of how deprivation of dietary fiber impacts susceptibility to a mucosal pathogen by the altered gut microbial ecology remains uncovered.

The murine mucosal pathogen Citrobacter rodentium forms attaching and effacing (A/E) lesions on the intestinal mucosa of the host and is often used as a model for human enteropathogenic and enterohemorrhagic Escherichia coli (EPEC and EHEC, respectively) infections. ${ }^{11}$ Thus, C. rodentium allows further study of how deprivation of dietary fiber impacts the complex ecological interactions between the gut microbiome, enteropathogens and the host. This, in turn, can aid in understanding the associations of Western-style dietary patterns with increased susceptibility to enteric pathogens. ${ }^{12}$ The lessons learned from

CONTACT Mahesh S. Desai mahesh.desai@lih.lu D Department of Infection and Immunity, Luxembourg Institute of Health, Esch-sur-Alzette 4354, Luxembourg 
such a model could furthermore inform strategies for designing customized diets to reduce the burden of enteric infections.

We previously showed that, when gnotobiotic mice colonized with a 14-member synthetic human gut microbiome (14SM) are fed a fiberfree diet, a community-wide proliferation of mucin-degrading bacteria causes erosion of the intestinal mucus barrier. ${ }^{13}$ This leads to lethal colitis by the rodent mucosal pathogen $C$. rodentium. ${ }^{13}$ It was uncertain whether our results from a gnotobiotic mouse model could be observed within specific-pathogen-free (SPF) mice, since the pathogen should face increased colonization resistance from a native, complex gut microbiota. Here, we investigated whether increased susceptibility to $C$. rodentium can be observed in fiberdeprived SPF mice and whether accompanying alterations in the gut homeostasis might contribute to the virulence of this mucosal pathogen.

\section{Methods}

\section{Ethical statement}

The animal experiments were approved by the Animal Welfare Structure of the Luxembourg Institute of Health (protocol number: DII-201714) and by the Luxembourgish Ministry of Agriculture, Viticulture and Rural Development (national authorization number: LUPA 2018/09). All experiments were performed according to the "Règlement grand-ducal du 11 janvier 2013 relatif à la protection des animaux utilisés à des fins scientifiques" based on the "Directive 2010/63/EU" on the protection of animals used for scientific purposes. The mice were housed in a specific-pathogen -free (SPF) facility according to the conditions stated in the recommendations of the Federation of European Laboratory Animal Science Association (FELASA).

\section{Experimental design and dietary treatment}

A total of fifty 6- to 8-week-old, female C57BL/6J mice purchased from Charles River Laboratories (Saint Germain Nuelles, 69210, France) were used for the experiments reported in this study. All mice were bred and housed in the same breeding room at
Charles River Laboratories and were derived from the same colony. After the arrival of all mice in the same transport box, mice were housed in the same individually ventilated cage (IVC) rack with up to five animals per cage. Throughout the experiments, all animals were exposed to 12 hours of light daily. Sterile water and diets were provided ad libitum. Upon arrival, all mice were maintained on a standard mouse chow, which we henceforth call a fiber-rich (FR) diet, for seven days. After the seven days of settling time, the cages were randomly allocated to one of the two dietary groups. The first group of five cages was maintained on the FR diet $(n=25)$, while the second group of five cages was switched to a fiber-free (FF) diet $(n=25)$ for $36-$ 40 days. Fecal samples were collected from both groups (FR, $n=10$ and FF, $n=10$ ) before the diet switch (d00) to confirm similar microbial colonization using 16S rRNA gene analyses and during the feeding period (D08 and D22) to analyze changes in microbial abundances. Prior to sacrificing and to infection with Citrobacter rodentium (D36), fecal samples were collected from all fifty mice for various readouts such as lipocalin (Lcn2) quantification (FR, $n=25$ and FF, $n=25$ ), $p$-nitrophenyl glycoside-based enzyme assay (FR, $n=4$ and FF, $n=4$ ), and $16 \mathrm{~S}$ rRNA gene sequencing (FR, $n=10$ and FF, $n=10$ ). After the feeding period, 10 mice (FR, $n=5$ and FF, $n=5$ ) were euthanized by cervical dislocation for mucus layer measurements, histological evaluation, colon length measurements and short-chain fatty acid quantification (cecal contents). Nine animals (FR, $n=4$ and FF, $n=5$ ) were maintained on the two diets for a total of 70 days to control for diet-specific weight alterations. Twenty animals were infected with approximately $2 \times 10^{8}$ colony-forming units (CFUs) of kanamycinresistant, wild-type C. rodentium strain (DBS 120) via intragastric gavage of $0.2 \mathrm{ml}$ bacterial culture (FR, $n=10$ and FF, $n=10$; five mice per cage). The same inoculum of $C$. rodentium was used to gavage all mice in both dietary groups. Fecal samples were collected daily following the infection. Mice were scored daily (none, mild, moderate, or severe) for the following criteria: reduced grooming habits resulting in dull coat, weight loss, activity, diarrhea, constipation, anorexia, hunched back position, and dehydration. The same scoring was also used for uninfected animals maintained on the two diets for 
70 days. Animals were euthanized if three of the criteria were scored as moderate, one of the physical appearance criterions was scored as severe, or if the animals lost $>20 \%$ of their initial body weight (measured on the day of infection, before the intragastric gavage of $C$. rodentium).

\section{Animal diets}

The fiber-free (FF) diet was manufactured by SAFE diets (Augy, France), as previously described, ${ }^{13}$ and was synthesized according to a modified version of the Harlan TD.08810 diet. The fiber-rich (FR) diet (4.23\% crude fiber) is the standard mouse chow in the local animal facility (Special Diets Service; Essex, UK; product code: 801722). The FF diet and the FR diet were both sterilized using $9 \mathrm{kGy}$ gamma irradiation.

\section{Mucus layer measurements and histological evaluation}

After euthanizing the animals by cervical dislocation, the gastrointestinal tracts were dissected, the colons were rapidly separated and fixed in methacarn solution for five hours $(60 \%$ dry methanol, $30 \%$ chloroform, 10\% glacial acetic acid) and then stored in $100 \%$ methanol until further processing. Samples were infiltrated with paraffin in a tissue processor, embedded in paraffin and subjected to either Alcian blue or hematoxylin and eosin (H\&E) staining on thin colonic sections $(5 \mu \mathrm{m})$. Alcian blue-stained sections were used for the mucus layer measurements, as described previously. ${ }^{13}$ Samples were deparaffinized in xylene $(2 \mathrm{x})$ for $8 \mathrm{~min}$ and $5 \mathrm{~min}$, hydrated in $96 \%, 80 \%$, and $70 \%$ ethanol (5 min each) and transferred to distilled water $(30 \mathrm{sec})$. Samples were stained in Alcian blue solution (30 $\mathrm{min}$ ) and washed under running tap water (2 $\mathrm{min})$, briefly rinsed in distilled water (30 sec), and dehydrated with $96 \%$ alcohol $(2 \mathrm{x})$ for $1.5 \mathrm{~min}$ and $2 \mathrm{~min}$. Samples were transferred to isopropanol (5 min) and treated with xylene $(2 \mathrm{x})$ for $5 \mathrm{~min}$ each and covered with a coverslip. Partially overlapping tile pictures over the entire colon length were taken by M. N. using a Zeiss Axio Observer Z1 Inverted Phase Contrast Fluorescence Microscope with the Zen software. The mucus layer measurements were performed in a single-blinded fashion by A. P. using ImageJ. Depending on the size of the fecal pellet, between 100 and 1300 measurements were performed and the average mucus layer thickness was calculated for each animal by averaging the measurements. $\mathrm{H} \& \mathrm{E}$-stained sections were used for blinded histological scoring. Samples were deparaffinized as described above and stained with hematoxylin solution (5 $\mathrm{min}$ ), washed in distilled water $(30 \mathrm{sec})$ and transferred to running tap water ( $5 \mathrm{~min}$ ). Samples were counterstained with $1 \%$ aqueous eosin (5 $\mathrm{min})$, washed under running tap water (4 min), dehydrated as described above and covered with a coverslip. Histological scoring was performed with a validated scale ${ }^{14}$ of $0-3$ with " 0 " representing no inflammation, "1" representing mild inflammation, "2" representing moderate inflammation and " 3 " representing severe inflammation. A total of 12 categories for histomorphological scores were used ${ }^{14}$ to evaluate 4-5 consecutive colonic regions and microscopic fields to determine the averages per group (e.g. infiltration of inflammatory cells, crypt hyperplasia, goblet cell loss, and distortion of colonic architecture; please see ${ }^{14}$ for detailed criteria about histomorphological scores).

\section{Citrobacter rodentium growth and fecal quantification}

C. rodentium was cultured aerobically from a cryostock on LB-agar plates supplemented with $50 \mu \mathrm{g} / \mathrm{ml}$ kanamycin. A single colony was incubated in Luria-Bertani (LB) broth without antibiotic supplementation at $37^{\circ} \mathrm{C}$ for 22 hours. The culture was then diluted in phosphate-buffered saline (PBS) to reach the concentration of approximately $2 \times 10^{8}$ CFU per $0.2 \mathrm{ml}$, which was verified by plating on LB-agar plates supplemented with $50 \mu \mathrm{g} / \mathrm{ml}$ kanamycin. Fecal sampling to determine $C$. rodentium CFUs was performed daily and samples were processed immediately. CFU detection continued to be performed daily for FF-fed mice until day 47 post infection, whereas no further CFU detection was performed for FR-fed mice upon pathogen clearance. The samples were weighed, homogenized in $1 \mathrm{ml}$ cold PBS, and $10 \mu \mathrm{l}$ of the fecal suspensions was plated in serial dilutions on LB-agar plates supplemented with $50 \mu \mathrm{g} / \mathrm{ml}$ kanamycin. The plates 
were incubated aerobically overnight at $37^{\circ} \mathrm{C}$ and the emerging colonies from the appropriate dilutions, ranging from $10^{4}$ to $10^{12}$, were counted. For CFU analysis of sacrificed animals, fresh cecal contents were collected and processed immediately, as described above.

\section{Lipocalin ELISA}

A total of $n=50$ samples (FR, $n=25$; FF, $n=25$ ) were used for this experiment. Lipocalin ( $\mathrm{Lcn} 2)$ concentration was determined for fecal samples stored at $-20^{\circ} \mathrm{C}$. Ice-cold PBS with $1 \%$ Tween 20 $(500 \mu \mathrm{l})$ was added to fecal pellets, followed by homogenization for $20 \mathrm{~min}$ at $4^{\circ} \mathrm{C}$ on a thermomixer. Samples were then centrifuged for $10 \mathrm{~min}$ at $18000 \times \mathrm{g}$ at $4^{\circ} \mathrm{C}$. Supernatants were stored at $20^{\circ} \mathrm{C}$ and $\operatorname{Lcn} 2$ detection was performed using the Mouse Lipocalin-2/NGAL DuoSet Elisa, R\&D Systems (Bio-Techne), according to the manufacturer's instructions.

\section{Colon length measurements}

Colons fixed in methacarn solution (see above) were transferred to a histology cassette and stored in $100 \%$ methanol. The lengths of colons were measured as previously described ${ }^{13}$

\section{Intestinal fatty acid analysis}

Flash-frozen cecal contents (30-100 mg) stored at $80^{\circ} \mathrm{C}$ were homogenized using five ceramic beads $(1.4 \mathrm{~mm})$ per tube with $500 \mu \mathrm{l}$ stock solution IS (2-Ethylbutyric acid, $20 \mathrm{mmol} / \mathrm{L}$ ) per $50 \mathrm{mg}$ of cecal content (VK05 Tough Micro-Organism Lysing Kit). Samples were homogenized at 4 $500 \times \mathrm{g}$ for $30 \mathrm{sec}$ at $10^{\circ} \mathrm{C}$ (Precellys 24 Homogenizer) and centrifuged for $5 \mathrm{~min}$ at 21000 $\mathrm{x} \mathrm{g}$ and $4^{\circ} \mathrm{C}$. Further processing of the homogenate and measurements of SCFAs were then performed using high-performance liquid chromatography (HPLC), as previously described. ${ }^{15}$

\section{P-Nitrophenyl glycoside-based enzyme assays}

Frozen fecal samples were stored and processed according to an established protocol. ${ }^{16}$ The activity of three host mucus targeting bacterial enzymes, $\beta$ -
$N$-acetylglucosaminidase, sulfatase, $\alpha$-fucosidase, and two dietary plant fiber glycan-targeting bacterial enzymes, $\alpha$-galactosidase, and $\beta$-glucosidase were investigated. Details about bacterial enzymes, their biological substrate and the chemical substrate used for activity detection can be found in Table 1 .

\section{Illumina sequencing of 165 rRNA genes and data analysis}

Fecal samples were stored at $-20 \mathrm{C}^{\circ}$ until bacterial DNA extraction and library preparations, which were performed as previously described. ${ }^{13}$ The cited protocol is a modified version of the protocol by Kozich et al. in which the V4 region of the $16 \mathrm{~S}$ rRNA gene is amplified using dual-index primers. ${ }^{17}$ Raw sequences have been deposited in the European Nucleotide Archive (ENA) under the study accession number PRJEB44016. The raw sequences were processed using the program mothur (v1.33.3) ${ }^{18}$ according to the MiSeq SOP published on the mothur website. ${ }^{17,19}$ Probabilistic modeling to cluster the microbial communities in metacommunities was performed in mothur based on the Dirichlet multinomial mixtures method. ${ }^{20}$ Alignment and classification of the sequences was done using the SILVA reference database (release 132). ${ }^{21}$ Chimeric sequences were removed using the VSEARCH tool. Microbial abundance figures were generated using the following packages in RStudio 4.0.2: phyloseq 1.34.0, ${ }^{22}$ ggplot2 $3.3 .3,{ }^{23}$ vegan $2.5 .7,{ }^{24}$ forcats $0.5 .1 .^{25}$ Alpha diversity analyses were

Table 1. Bacterial enzymes and chemical substrates used for activity detection.

\begin{tabular}{|c|c|c|c|}
\hline Bacterial enzyme & $\begin{array}{l}\text { Biological } \\
\text { substrate }\end{array}$ & $\begin{array}{c}\text { Chemical substrate } \\
\text { used for activity } \\
\text { detection }\end{array}$ & Supplier \\
\hline Sulfatase & $\begin{array}{l}\text { Host mucus } \\
\text { glycans }\end{array}$ & $\begin{array}{l}\text { Potassium } \\
\text { 4-nitrophenyl- } \\
\text { sulfate }\end{array}$ & $\begin{array}{l}\text { Sigma } \\
\text { Aldrich, } \\
\text { Cat\#N3877 }\end{array}$ \\
\hline $\begin{array}{l}\beta \text {-N-Acetyl- } \\
\quad \text { glucosaminidase }\end{array}$ & $\begin{array}{l}\text { Host mucus } \\
\text { glycans }\end{array}$ & $\begin{array}{l}\text { 4-Nitrophenyl } \\
\text { N-acetyl- } \beta \text { - } \\
\text { D-glucosamidine }\end{array}$ & $\begin{array}{l}\text { Sigma } \\
\text { Aldrich, } \\
\text { Cat\#N9376 }\end{array}$ \\
\hline a-Fucosidase & $\begin{array}{l}\text { Host mucus } \\
\text { glycans }\end{array}$ & $\begin{array}{l}\text { 4-Nitrophenyl a- } \\
\text { L-fucopyranoside }\end{array}$ & $\begin{array}{l}\text { Sigma } \\
\text { Aldrich, } \\
\text { Cat\#N3628 }\end{array}$ \\
\hline a-Galactosidase & $\begin{array}{l}\text { Dietary plant } \\
\text { fiber } \\
\text { glycans }\end{array}$ & $\begin{array}{l}\text { 4-Nitrophenyl a- } \\
\text { D-galacto- } \\
\text { pyranoside }\end{array}$ & $\begin{array}{l}\text { Sigma } \\
\text { Aldrich, } \\
\text { Cat\#N0877 }\end{array}$ \\
\hline$\beta$-Glucosidase & $\begin{array}{l}\text { Dietary plant } \\
\text { fiber } \\
\text { glycans }\end{array}$ & $\begin{array}{l}\text { 4-Nitrophenyl } \beta \text { - } \\
\text { D-gluco-pyranoside }\end{array}$ & $\begin{array}{l}\text { Sigma } \\
\text { Aldrich, } \\
\text { Cat\#N7006 }\end{array}$ \\
\hline
\end{tabular}


performed on unfiltered data. The Principal Coordinates of Analysis (PCoA) plot is based on Bray-Curtis dissimilarity index, after filtering out taxa not seen at least 10 times in at least $20 \%$ of the samples. The spatial means of the FR diet-fed mice and FF diet-fed mice clusters at the end of the feeding period were significantly different by PERMANOVA using adonis $(p=0.001)$, although a significant betadisper test $(p=0.001)$ means that this finding could be an artifact of the heterogenous dispersions. The heatmap was generated based on the top 50 significant OTUs determined using DESeq2 1.30.1; ${ }^{26}$ all OTUs shown are significant based on an adjusted $p$-value $<0.01$. The heatmap shows $\log 2$ fold-change for data rarefied to the minimum library size and filtered (minimum 10 counts in $20 \%$ of samples) displaying the fold-changes in abundance of each OTU, relative to the average abundance of that OTU in the comparator dietary group. Samples where the read count is zero are presented as infinitely negative values. In cases where all samples in a group had zero read counts, all samples with a non-zero value in the comparator group are then infinitely positive relative to the other group's zero average count. Adjusted $p$-values were obtained using the Benjamini-Hochberg procedure to correct for multiple comparisons.

\section{Results and discussion}

Six to eight-week-old, age-matched specificpathogen-free (SPF) female C57BL/6J mice were maintained on a mouse chow, which, with a fiber content of $4.23 \%$ crude fiber, we consider to be a fiber-rich (FR) diet. Ten animals were switched to a fiber-free (FF) diet and were continuously fed the FF diet for a 36-40 days "feeding period" (Figure 1a). As controls, the remaining C57BL/6J mice were maintained on the FR diet. The FR diet contained naturally milled food ingredients with crude plant fiber sources, such as corn, soybean, and wheat, whereas the isocaloric FF diet lacked such plant polysaccharides and instead contained increased levels of glucose. ${ }^{13}$ Throughout the feeding period, the FF-fed mice did not exhibit any physiological irregularities (data not shown) or weight loss.
Fiber deprivation leads to an increase in potential mucus-degrading bacterial taxa in SPF mice

Before, during and at the end of the feeding period (d00, d08, d22 and d36), 16S rRNA gene sequencing (Illumina MiSeq platform) was performed in two independent experiments using DNA extracted from the mouse fecal samples. The results were compared to the FR-fed mice to evaluate changes in microbiome composition in response to diets with different fiber content (Figure 1b-d). Alpha diversity between groups was not significantly different using the Chao 1 richness estimate or by Shannon and inverse Simpson indices, which account for the evenness of the detected taxa (data not shown). Principal Coordinates of Analysis (PCoA) based on Bray-Curtis dissimilarity (Figure 1b) confirmed similar microbial composition before the diet switch (d00) and statistically significant clusters by diet during the feeding period (d08 and $\mathrm{d} 22$ after diet switch). The PCoA furthermore revealed significant diet-specific clustering by PERMANOVA $(p=0.001)$ after 36 days of feeding. Although the dispersion was significantly different between the diets at $\mathrm{d} 36$ ( $p=0.001$ ), it is reasonable to conclude that the spatial medians are indeed significantly different since the design is balanced. ${ }^{27}$ On the phylumlevel, Proteobacteria and Firmicutes were significantly higher among FF-fed mice, whereas Bacteroidetes was enriched in FR-fed mice (Figure 1c). Family-level analysis revealed heterogeneous changes within the Bacteroidetes phylum, as Muribaculaceae and Prevotellaceae were enriched in FR-fed mice, but Rikenellaceae, Marinifilaceae, and Tannerellaceae were higher among FF-fed mice (Figure 1d). Firmicutes belonging to Peptostreptococcaceae, Streptococcaceae, and Clostridiales Family XIII, were higher among FFfed mice, as were Proteobacteria belonging to Burkholderiaceae and Desulfovibrionaceae families (Figure 1d). An expansion of Proteobacteria has been associated with intestinal epithelial dysfunction. $^{28}$ Peptostreptococcaceae have been found to be enriched in patients with colorectal cancer $^{29}$ and has been associated with a decrease in mucus layer thickness. ${ }^{30}$ Furthermore, increased levels of Bacteroidetes over Firmicutes, as shown in FR-fed animals (Figure 1d), has been previously 


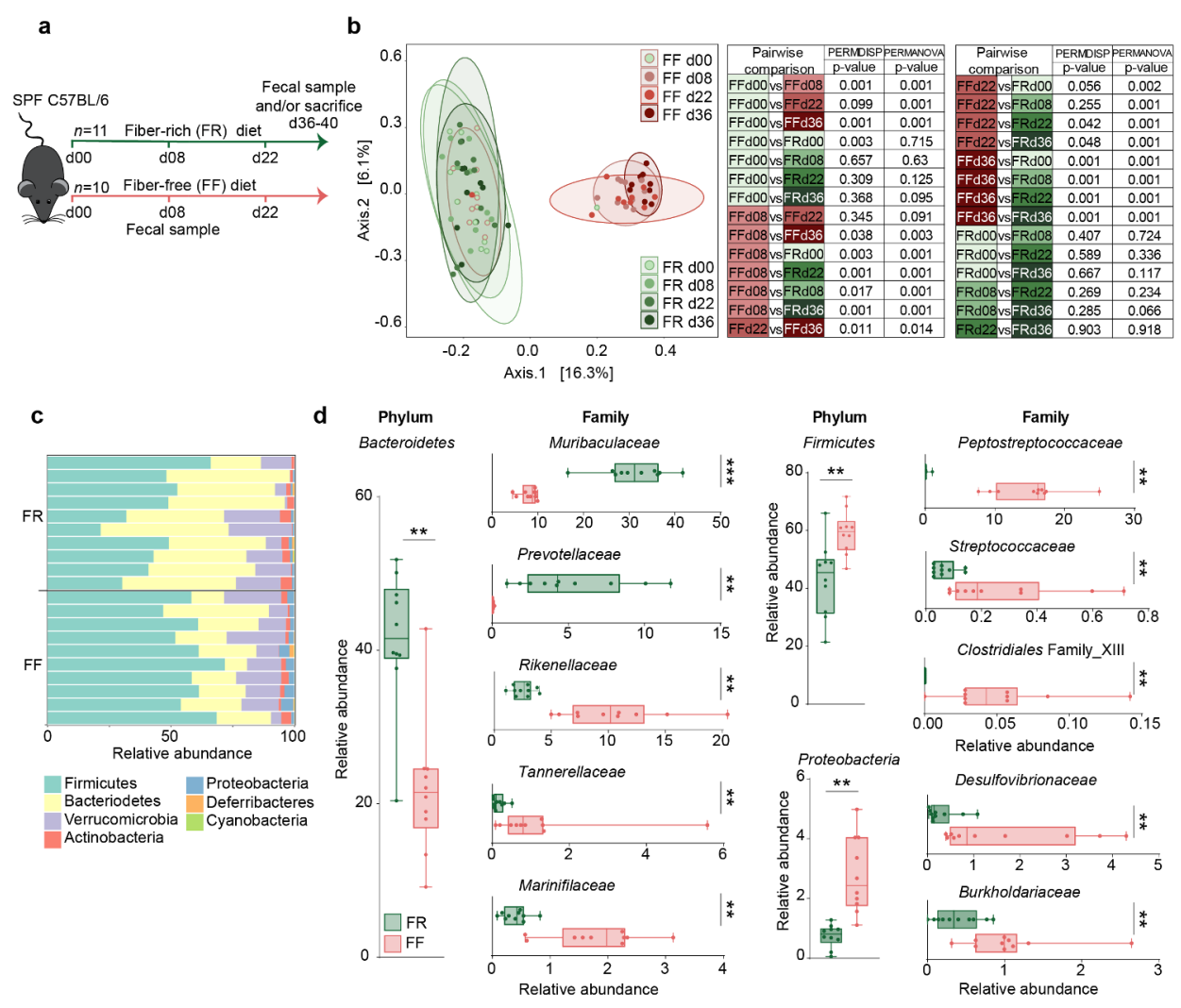

Figure 1. Fiber deprivation in mice harboring a complex microbiome results in changes in bacterial families. Green: FR-fed mice; Red: FF-fed mice. ${ }^{*}=p<0.05 ;{ }^{* *}=p<0.01 ;{ }^{* * *}=p<0.001$. (a) Experimental schedule. 6 to 8 week-old female specific-pathogen-free (SPF) C57BL/6J mice were continued on a fiber-rich (FR) diet or switched to a fiber-free (FF) diet for a feeding period of 36-40 days. Fecal samples were collected before diet switch (d00) and at d08, d22 and d36 after the diet switch. At the end of the 36-40 days feeding period, mice were sacrificed for various readouts. FR, $n=11$ and FF, $n=10$. (b) Left: Principal coordinates analysis (PCoA) of the fecal microbial communities of FR and FF mice before the diet switch (d00), on d08, d22 and after 36 days of feeding the two different diets, based on Bray-Curtis dissimilarity index. Ellipses represent $95 \%$ confidence interval for each group. Right: Statistical analysis between all dietary groups on d00, d08, d22 and d36 after diet switch. The difference in spatial means of FR and FF diet clusters was significant by PERMANOVA testing using adonis $(p=0.001)$, however, the dispersions (PERMDISP) were also significantly different using a permuted betadisper function ( $p=0.001$ ). $\mathrm{FR}, n=10$ and FF, $n=10$. Adjusted $p$-values were obtained using the Benjamini-Hochberg procedure to correct for multiple comparisons. (c) Barplot of relative microbial abundances of the bacterial phyla after 36 days of feeding among FR- $(n=10)$ and FF-fed $(n=10)$ mice. (d) Boxplots displaying significant changes in the relative abundance $(\%)$ of Bacteroidetes, Firmicutes and Proteobacteria between FR- $(n=10)$ and FF-fed $(n=10)$ mice. Boxplots display significant changes in relative abundance (\%) of bacterial families between FR- and FF-fed animals, sorted by their corresponding phylum (left). Whiskers display minimum and maximum. Mann-Whitney test, two-tailed.

linked with a decreased $C$. rodentium susceptibility. ${ }^{31}$ Analysis of $\log 2$ fold-change on an OTU level using DESeq2 reveals discrete changes between the dietary conditions (Figure 2). We exclude a cage effect based on the Dirichlet multinomial mixtures method, ${ }^{20}$ which identified only two microbial community clusters that correspond to the diet. These clusters are evident in the phylogenetic tree of the heatmap, depicting samples from individual animals and their corresponding cages (Figure 2). An upregulation of specific OTUs belonging to the bacterial genera Lachnospiraeceae,
Ruminococcaceae, and Oscillibacter could be detected in fiber-deprived animals compared to the control group (Figure 2). An increased abundance of Lachnospiraeceae spp. has previously been reported to be associated with the increased susceptibility to adherent-invasive Escherichia coli (AIEC) infection. ${ }^{32}$ Furthermore, Ruminococcaceae spp. $^{33}$ Lachnospiraceae spp., Clostridiales spp., Desulfovibrionales spp., and Oscillibacter spp. have been shown to correlate with the production of branched chain fatty acids (BCFAs), such as isovaleric and isobutyric acid. ${ }^{34}$ 


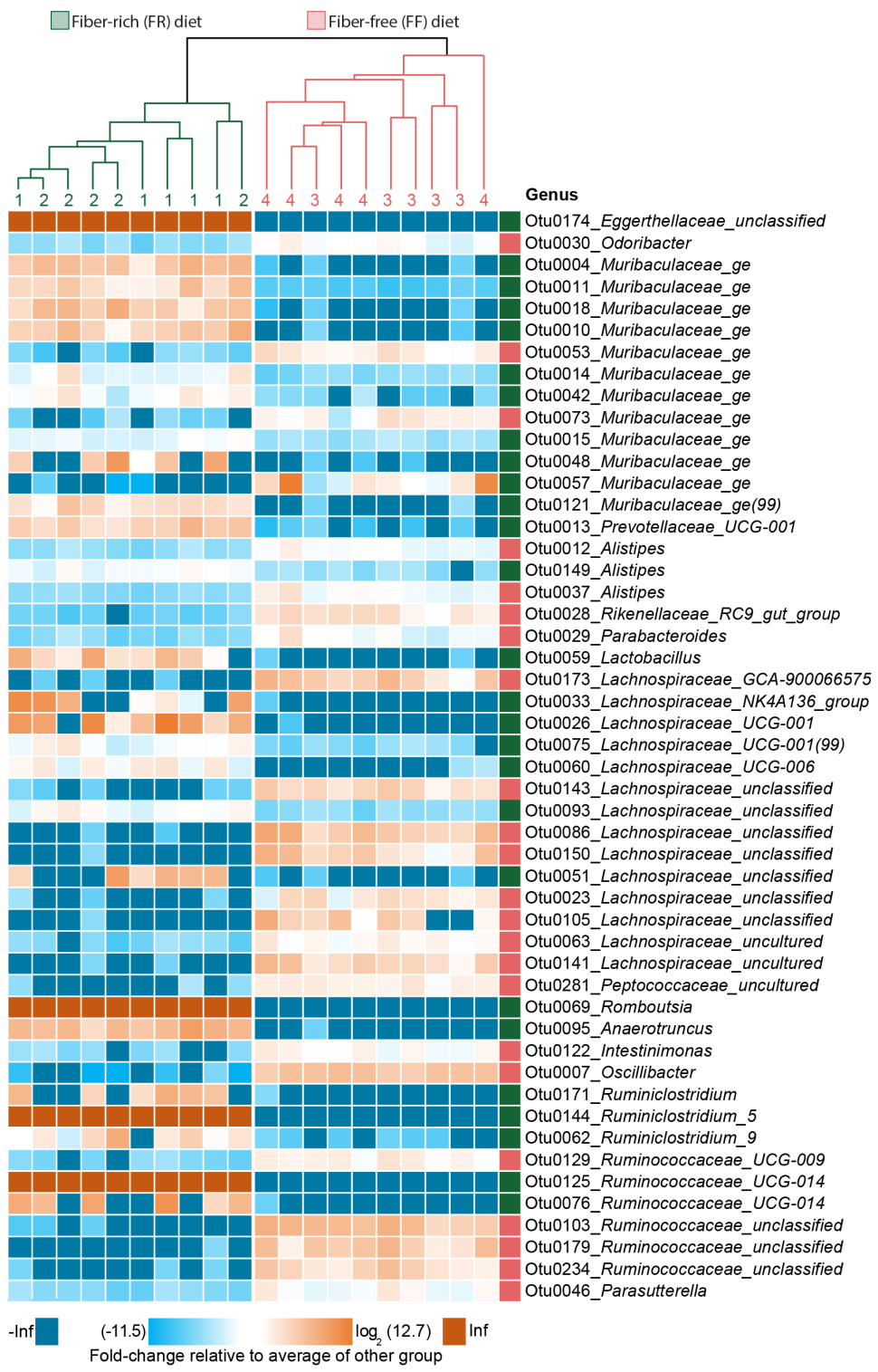

Figure 2. Fiber deprivation in mice harboring a complex microbiome results in changes in bacterial families with no detectable cage effect. At the top of the heatmap, a phylogenetic tree displays clustering by diet (FR = green, FF = red). Green numbers (cages 1 and 2 ) and lines indicate cages of FR-fed mice. Red numbers (cages 3 and 4) and lines indicate cages of FF-fed mice. FR, $n=10, F F, n=10$ with $n=5$ animals per cage. The heatmap displays fold-changes in abundance of top 50 operational taxonomic units (OTUs) that were identified as significantly different between FR- and FF-fed mice using DESeq2, based on the adjusted $p$-value; FR, $n=10, \mathrm{FF}, n=10$. Adjusted $p$-values were obtained using the Benjamini-Hochberg procedure to correct for multiple comparisons. The log ${ }_{2}$-transformed fold-change of each OTU (rows) in each sample (columns) is calculated relative to the average abundance of the other group. OTUs labeled with green squares to the left are enriched in FR-fed mice, wheras OTUs labeled with red squares are enriched in FF-fed mice.

In line with these and previous results, we investigated whether dietary fiber deprivation resulted in altered intestinal fatty acid concentrations by measuring levels of SCFAs (acetate, butyrate, propionate, and valerate) and BCFAs (isobutyrate and isovalerate) in cecal contents of FR-fed and FF-fed mice at the end of the feeding period. We detected significantly increased levels of the SCFAs acetate, propionate and butyrate in FR-fed mice compared to FF-fed mice, while amounts of all detected BCFAs were significantly lower compared to fiber-deprived mice (Figure 3a). While SCFAs are generated largely by the microbial fermentation of dietary fibers, ${ }^{35}$ intestinal BCFAs are mainly the result of bacteria-mediated dietary protein metabolism. ${ }^{36}$ 
a
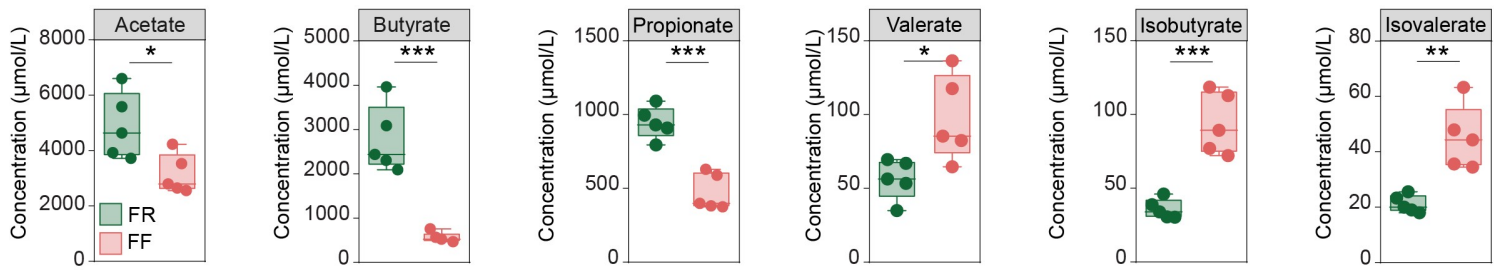

b
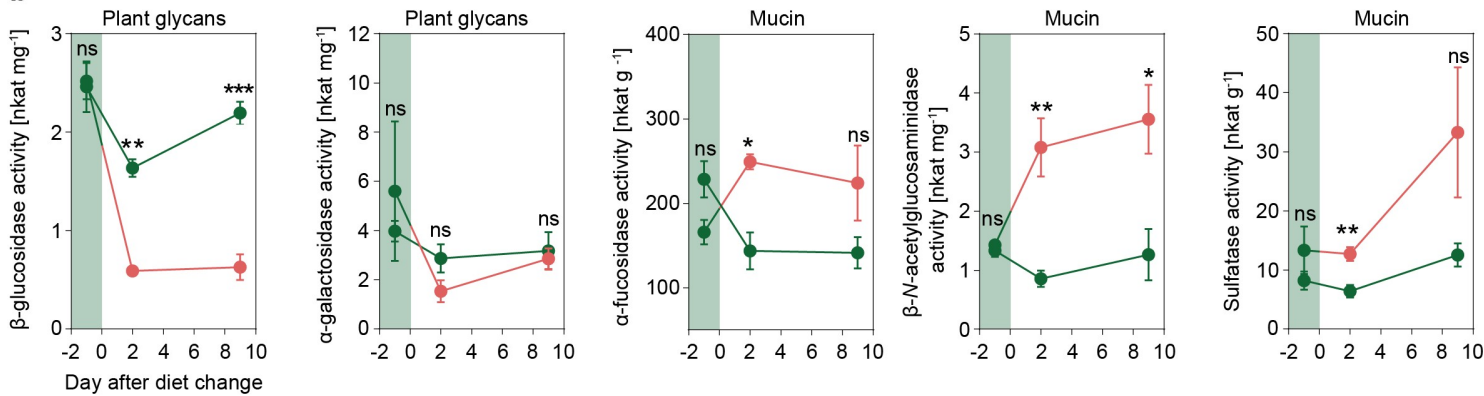

c
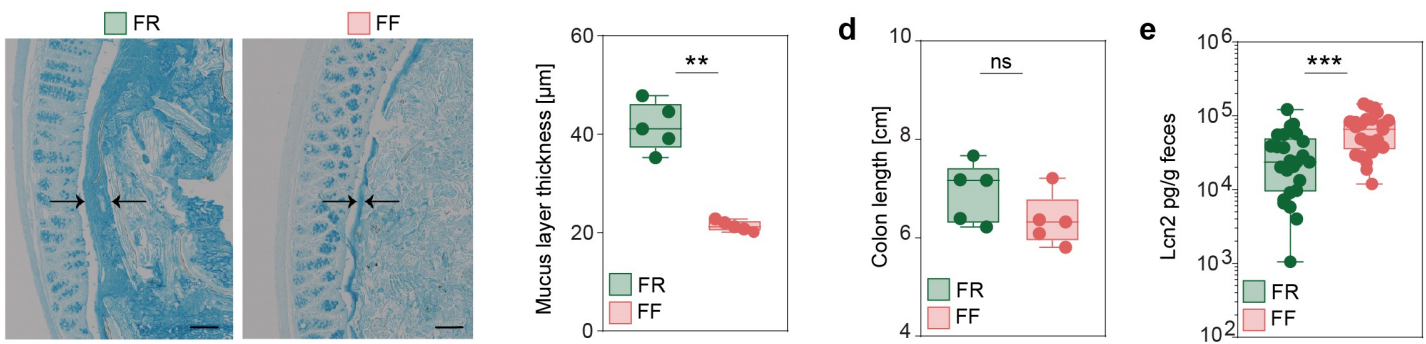

Figure 3. Fiber deprivation in mice harboring a complex microbiome results in changes in bacterial enzyme activity and levels of mucosal barrier integrity markers. Green: FR-fed mice; Red: FF-fed mice. ${ }^{*}=p<0.05 ;{ }^{* *}=p<0.01 ;{ }^{* *}=p<0.001$. (a) SCFA and BCFA concentrations in cecal contents in $\mu \mathrm{mol} / \mathrm{L}$ after 40 days of feeding in FR- $(n=5)$ and FF-fed $(n=5)$ animals. Unpaired t-test, two-tailed. (b) Results for $p$-nitrophenyl glycoside-based enzyme assay from fecal samples of FR-fed $(n=4)$ and FF-fed $(n=4)$ animals. Evaluation of five different bacterial enzymes. Plant glycans: $\beta$-glucosidase, $a$-galactosidase. Mucin: $\alpha$-fucosidase, $\beta$ - $N$-acetylglucosaminidase, and sulfatase at three different time points. Day 1 before diet switch to FF diet, day 2 after diet switch to FF diet and day 9 after diet switch to FF diet. Green area indicates FR feeding period before diet switch to FF diet. Error bars represent SEM. Unpaired t-test, two-tailed. (c) Left panel: Alcian blue-stained $5 \mu \mathrm{m}$ thin sections of the colonic mucus layer of FR-fed and FF-fed animals. Black arrows indicate thickness of the colonic mucus layer. Scale bar $=100 \mu \mathrm{m}$. Right panel: Statistical analysis of mucus layer measurements of FR-fed $(n=5)$ and FF-fed $(n=5)$ animals. Mann-Whitney test, two-tailed. (d) Colon length in FR- $(n=5)$ and FF-fed $(n=5)$ mice after 40 days of feeding. Mann-Whitney test, two-tailed. (e) Levels of lipocalin in fecal supernatant, normalized on fecal weight for FR- $(n=25)$ and FFfed $(n=25)$ animals after 36-40 days of feeding. Mann-Whitney test, two tailed.

Among other microbial protein fermentation products, such as phenol, biogenic amines, hydrogen sulfide and $p$-cresol, ${ }^{37}$ BCFAs are associated with an increased colonic epithelial cell permeability in vitro, ${ }^{38}$ whereas SCFAs are reported to maintain mucosal barrier integrity by increasing mucin2 glycoprotein (MUC2) expression, ${ }^{39}$ enhancing colonic tight-junction assembly, ${ }^{40}$ and stimulating antimicrobial peptide secretion. ${ }^{41}$ Furthermore, changes in intestinal butyrate concentration is known to affect susceptibility of C. rodentium ${ }^{42}$ and oral administration of butyrate ameliorates C. rodentium-induced inflammation via enhanced IL-22 production. ${ }^{43}$

Additionally, specific species within the Rikenellaceae (Alistipes), ${ }^{44,45}$ Lachnospiraceae ${ }^{46,47}$ and Muribaculaceae ${ }^{45}$ families are thought to possess the capacity to degrade mucus. Thus, in line with our 14 SM model, ${ }^{13}$ our results suggest that the deprivation of dietary fiber may also increase mucus-degrading populations in the SPF mice containing their native gut microbiota. An increase in 
Desulfovibrionaceae family (Figure 1d) is consistent with the significant increase of Desulfovibrio piger (family: Desulfovibrionaceae), which was previously observed in fiber-deprived 14SM-colonized gnotobiotic mice. ${ }^{13}$ An increase in these sulfate-reducing bacteria indicates higher availability of sulfate groups that are used as an electron acceptor by this group of bacteria. A possible source of this increased sulfate could be the terminal sulfate groups on the colonic mucin-associated glycans. ${ }^{10}$

\section{A dietary fiber-deprived gut microbiota erodes the colonic mucus layer in SPF mice}

Given the relevance of mucus erosion on pathogensusceptibility of fiber-deprived mice in a gnotobiotic mouse model, ${ }^{13}$ we evaluated whether the increase in these potentially mucus-degrading taxa resulted in the increased activities of microbial enzymes that are involved in the degradation of host-secreted colonic mucus. We studied activities of five different enzymes in the mouse fecal samples before, and after a switch to the FF diet. Our results show a significant increase in the activities of three microbial enzymes, namely $\alpha$-fucosidase, $\beta$ $N$-acetylglucosaminidase and sulfatase (Figure $3 \mathrm{~b}$ ), that are involved in colonic mucus degradation. Conversely, the activity of $\beta$-glucosidase, an enzyme involved in the degradation of plant glycans, was significantly decreased in the FF-fed animals.

To assess the impact of the increased activities of these mucus-specific enzymes on the mucus layer, we performed measurements of the colonic mucus layer thickness, using fixed colonic tissue samples stained with Alcian blue. ${ }^{13}$ The mucus measurements revealed significantly decreased mucus layer thickness in fiber-deprived mice compared to the FR-fed mice (Figure 3c). Taken together, decreased SCFA levels and reduced mucus layer thickness suggest impairment of the intestinal mucosal barrier in fiber-deprived mice.

In order to evaluate inflammatory reactions in the colonic tissue in response to the potential mucosal barrier impairment in the FF-fed mice, we measured colon lengths and the levels of lipocalin (Lcn2), a sensitive marker capable of detecting low-grade inflammation, in fecal contents of the FR- and FFfed mice after the feeding period. There was a trend toward reduced colon lengths in the FF-fed animals compared to the FR-fed animals (Figure 3d), athough this was not statistically significant. Fecal Lcn2 levels, however, were significantly increased in fiber-deprived mice (Figure 3e), indicating an increased inflammatory tone in FF-fed mice without pronounced colonic inflammation. Furthermore, histopathological evaluation ${ }^{14}$ of colonic hematoxylin/eosin-stained sections did not reveal significant differences between FR- and FF-fed mice (histology data not shown; average histological score for FR-fed mice 0.017 (SD, 0.058) and for FF-fed mice 0.12 (SD, 0.232); Mann-Whitney test, two tailed, $p=0.342$ ). These observations were in line with the previous observation in our gnotobiotic mouse model ${ }^{13}$ and prompted us to investigate whether the diet-induced alterations in the microbiome composition and its associated effects on the markers of mucosal barrier integrity impacted the susceptibility of fiberdeprived mice to infection with $C$. rodentium.

\section{Deprivation of dietary fiber in SPF mice promotes susceptibility to $C$. rodentium}

To test our hypothesis, we infected FF-fed and control FR-fed mice with $C$. rodentium. Weight and general appearance were monitored daily for up to 47 days post infection (dpi), and fecal C. rodentium $(\mathrm{Cr})$ colony forming units (CFUs) were assessed until all animals cleared the pathogen or had to be euthanized (Figure 4a). FR and FF animals without infection showed no significant weight differences in two dietary groups for up to 70 days after switch to the FF diet (Figure $4 \mathrm{~b}$ ). The FF-fed animals infected with $\mathrm{Cr}$ demonstrated significantly higher weight loss compared to the FRfed animals, with several animals requiring euthanasia owing to $>20 \%$ weight loss (Figure $4 c$ ). In line with the observed weight loss, survival curves of infected animals fed the two different diets showed only a $40 \%$ survival rate in FF-fed mice, whereas $100 \%$ of the mice in the FR-fed group survived (Figure 4d).

Moreover, FF-fed mice showed overall delayed $\mathrm{Cr}$ clearing capacities and elevated CFUs in fecal samples until 23 dpi (Figure 4e). While the FR-fed mice showed rapidly decreasing CFUs after $11 \mathrm{dpi}$ and all mice of this group cleared the pathogen completely by 19 dpi (Figure 4e), the FF-fed mice took longer $(24 \mathrm{dpi})$ to clear the pathogen. 
a
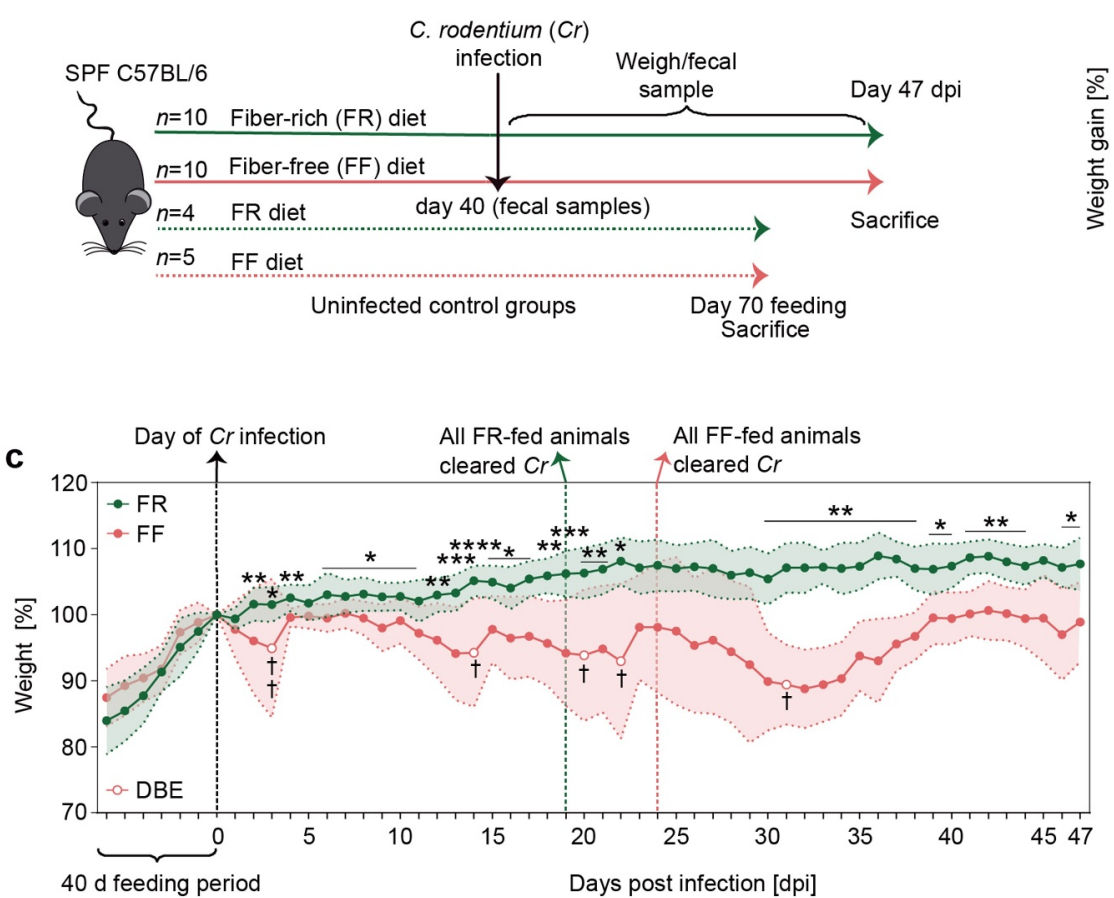

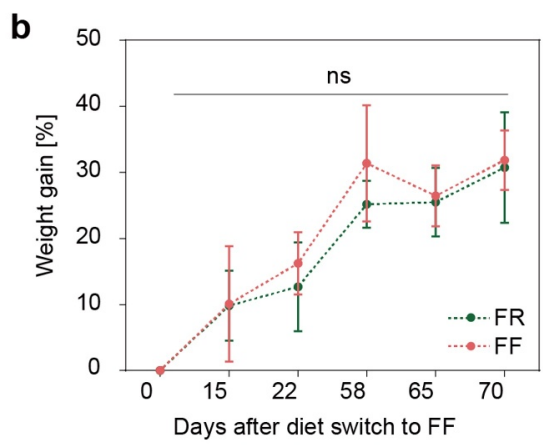

d

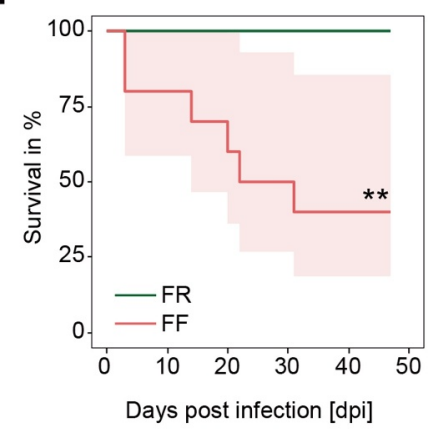

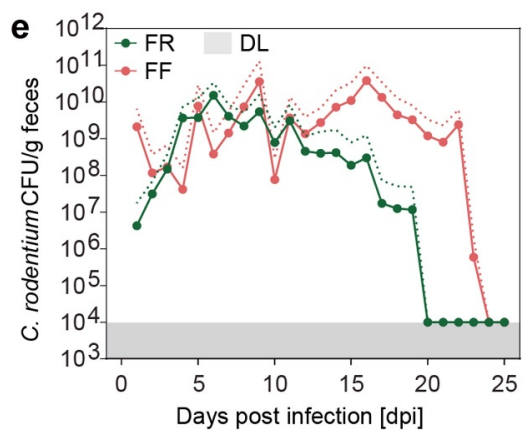

f

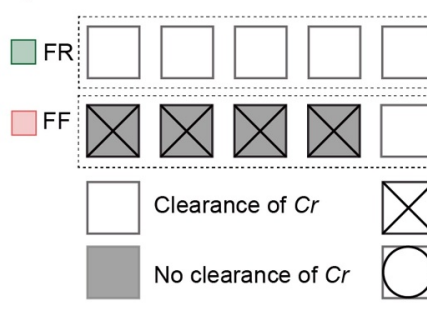

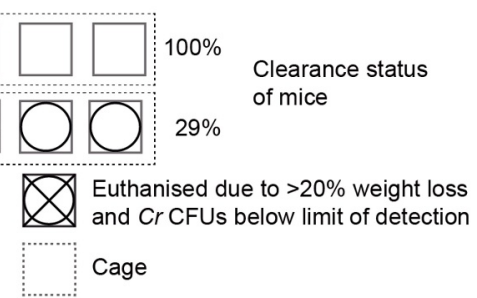

Fiber-rich (FR) diet
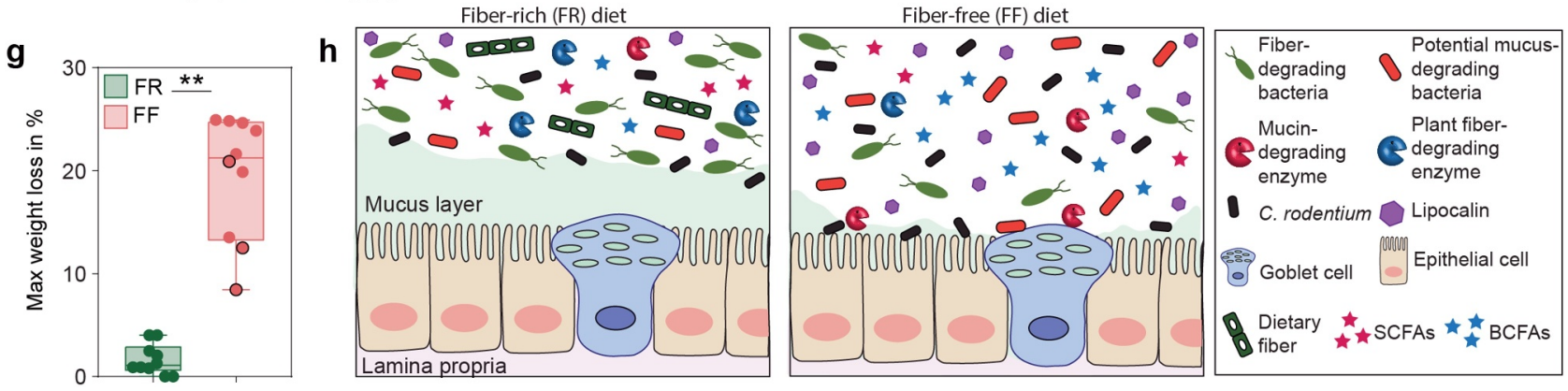

Figure 4. Fiber-deprivation in mice is associated with a higher susceptibility to C. rodentium infection. Green: FR-fed mice; Red: FF-fed mice. ${ }^{*}=p<.05 ; * *=p<0.01 ;{ }^{* * *}=p<0.001 ;{ }^{* * * *}=p<0.0001$. a) Experimental schedule. Animals were fed the FR diet or the FF diet ( $F R, n=10$ and FF, $n=10$ ) for 40 days and infected via intragastric gavage with $2 \times 10^{8}$ colony forming units (CFU) in $0.2 \mathrm{ml}$ culture of C. rodentium $(\mathrm{Cr})$. Fecal samples were collected before the infection and used for various readouts. Animals were monitored daily for 47 days post infection (dpi). Mice were euthanized when they lost $20 \%$ of the body weight compared to the initial day of infection. Dotted red and green arrow: animals ( $F R, n=4$ and FF, $n=5$ ) were fed the respective diets as uninfected control groups for 70 days. (b) Mean weight in percent of FR-fed and FF-fed animals over a time period of 70 days after the diet switch. FR: $n=4$ and FF: $n=5$. Green and red error bars represent SD. ns = not significant. MannâWhitney test, two-tailed (c) Left of zero: Mean weight as a percent of reference weight to the day of diet switch of FR-fed ( $n=15 ; 5$ animals used for earlier readouts without infection) and FF-fed ( $n=15 ; 5$ animals used for earlier readouts without infection) animals during the 40-days feeding period. Dotted black line at d0: day of $\mathrm{Cr}$ infection and reference weight. Right of zero: Mean weight as a percent of reference weight (d0) in FR-fed $(n=10)$ and FF-fed $(n=10)$ animals after the infection with $\mathrm{Cr}$. Dotted green or red line: all FR- or FF-fed animals cleared $\mathrm{Cr}$, respectively. White circles indicate time points where animals had to be euthanized due to weight loss beyond $20 \%$, compared to the reference weight (d0). Black cross 
indicates number of animals that had to be euthanized. DBE = death before experimental endpoint. Red and green areas represent SD. Mann-Whitney test, two-tailed. (d) Cumulative number of individuals at risk over time among FR- $(n=10)$ and FF-fed $(n=10)$ animals infected with Cr. Log-rank test. Red area represents confidence interval. (e) Cr CFUs per gram fecal content of FR- ( $n=10)$ and FF-fed $(n=10)$ animals. For days where CFUs were below the detection limit of $10^{4}$ CFUs, the detection limit of $10^{4}$ CFUs was used. No CFUs values were included if no fecal samples could be obtained or if an animal had to be euthanized. Red and green dotted lines represent $\mathrm{SD}$. DL $=$ detection limit of $10^{4}$ CFUs. (f) Graphic representation of the clearance rates of $\mathrm{Cr}$ susceptible animals, FR, $n=10$ and FF, $n=10$. Animals and treatment groups sorted by their caging (5 animals/cage) (dotted lines) and dietary experimental groups. Each symbol represents one mouse with the respective clearance status and $\mathrm{Cr}$ susceptibility. (g) Maximal weight loss of each individual animal in percent (FR, $n=10$ and FF, $n=10$ ). Maximal weight loss is displayed in percent of the day during the experiment where the highest weight loss was detected. Black circles: Animals displaying Cr CFUs below limit of detection throughout the experiment. Wilcoxon matched-pairs signed rank test. Two-tailed. (h) Graphical summary on diet-driven changes within gut homeostasis on $\mathrm{Cr}$ susceptibility. Left: Homeostatic conditions in FR-fed mice. Right: Changes in dietary fiber-deprived mice within gut homeostasis. Far right: Legend.

Although three FF animals failed to show detectable CFUs, one out of these three FF animals had to be euthanized on 31 dpi due to weight loss (Figure 4c), suggesting that fiber deprivation acts in favor of a lethal $\mathrm{Cr}$ phenotype even when CFUs are below the detection limit. These results suggest that dietary fiber deprivation is associated with a delayed $\mathrm{Cr}$ clearance (Figure 4e) as well as reduced rates of clearance (Figure $4 \mathrm{f}$ ) and an overall higher weight loss (Figure $4 \mathrm{~g}$ ). The infection by $\mathrm{Cr}$ is usually self-limiting in healthy mice because the commensal gut bacteria are able to outcompete the pathogen by competing for nutritional resources, such as monosaccharides. ${ }^{48,49}$

A lethal infection phenotype like the one we observed in the FF-fed wild-type mice has typically been observed in mice lacking essential genes that protect from $\mathrm{Cr}$ clearance and invasion, such as $M u c 2^{50}$ or genes encoding the cytokines IL-10 and IL-22. ${ }^{51,52}$ Our previous ${ }^{13}$ and current studies show that such a lethal phenotype could be generated in wild-type mice merely by eliminating plant fibers from the diet. Given that $M u c 2^{-/-}$mice exhibit a similar lethal phenotype to $C r,{ }^{50}$ it is plausible that the fiber-deprived gut microbiota-led erosion of the mucus layer contributes to the pathogenicity. Nevertheless, germ-free mice, which naturally possess a thinner mucus layer, on either the FR and FF diets do not exhibit a lethal colitis following the $\mathrm{Cr}$ infection on either the FR or FF diet. ${ }^{13}$ Thus, together with our previous study, ${ }^{13}$ the current study further supports the role of a fiber-deprived, mucus-eroding gut microbiota in driving susceptibility to $\mathrm{Cr}$. Notably, no systemic spread of $\mathrm{Cr}$ into other organs, such as liver or spleen, could be detected in FF-fed mice that had to be euthanized due to $>20 \%$ weight loss (data not shown). These results indicate a local impact of $\mathrm{Cr}$ in the cecum and colon, possibly driven by differences in the microbiota composition and microbial mucus erosion, that drives the lethal phenotype.

\section{Conclusion}

Our results indicate a crucial role of fiber intake on the maintenance of mucosal barrier integrity governed by the microbial ecology of the native, complex mouse microbiome, which plays an important role in protecting against infection with a mucosal pathogen. Different microbiota compositions, in mice from distinct mouse facilities, are responsible for a variable colitis phenotype to $\mathrm{Cr}$ infection. ${ }^{42}$ Here, we show that mice possessing the same starting microbiota (Figure 1b), when fed a fiberdeprived diet, undergo a change in the composition and function of the gut microbiota (Figure 1cFigure 3), which collectively contributes to a lethal phenotype to $\mathrm{Cr}$ (Figure 4).

A recent study showed that the WSD as compared to a standard grain-based chow (GBC) impedes the initial colonization of $\mathrm{Cr}$, although WSD leads to alterations in the gut microbiota in such a way that $\mathrm{Cr}$ cannot be outcompeted by the microbiota; ${ }^{53}$ hence, $\mathrm{Cr}$ in the mice fed WSD cannot be cleared or the clearance is delayed. Here, we observed a similarly delayed clearance of $\mathrm{Cr}$ in mice fed the FF diet. However, the difference in the phenotype we observe in the FF diet and the one observed in the WSD-fed mice could be rooted in important differences in the composition of these two diets. While the WSD contains nearly twice the amount of \%kcal derived from fat as compared to the FF diet (60\% vs. $34.1 \%)$, the FF diet contains more than twice the calories derived from 
carbohydrates as compared to the WSD ( $42.4 \%$ vs $20 \%)$. Other reasons for differences in the $\mathrm{Cr}$ infection phenotypes observed with the FF diet and the WSD could be related to the differences in the native mouse gut microbiota and/or differences in the initial pathogen CFU gavaged in the mice.

Compositional differences between the FR and FF diets other than the fiber content, such as increased amounts of simple sugar in the FF diet, raise a caveat in directly associating the lethal phenotype observed in FF-fed mice with the absence of plant fiber. Although we cannot rule out potential effects of other compositional differences between the FR and FF diets, using our 14SM community, we have documented that the two diets lead to a major impact on the fiber- versus mucin-utilization dynamics of the gut microbiota. ${ }^{13}$ Furthermore, our current data clearly show that the FF diet leads to enhanced mucin degradation by the gut microbiota, which occurs as a result of fiber deprivation. As SCFAs are derived abundantly from microbial fermentation of dietary fiber, ${ }^{35}$ the decreased butyrate levels of FF-fed mice compared to the control group can be linked to the dietary fiber deprivation. Butyrate provides up to $80 \%$ of the required energy for colonocytes to maintain colonic homeostasis. ${ }^{54,55}$ The decreased butyrate levels in FF-fed mice might lead to a more vulnerable mucosal barrier, thereby contributing to the increased lethal phenotype when challenged with an enteric pathogen. Thus, it is likely that the absence of plant fiber in the FF diet plays a crucial role on the lethal phenotype observed in this study.

Further investigations are needed to determine specific dietary strategies and/or usage of various reduced microbial communities in gnotobiotic mouse models to understand which specific bacterial taxa, their associated bacterial enzymes or microbial cross-talk with the host immune system modulate susceptibility to $\mathrm{Cr}$ infection. A follow-up study to the current one needs to utilize various reduced synthetic communities, such as removing some or all four mucus degraders from our 14SM model, ${ }^{13}$ to better understand the mechanisms of how mucin-degrading bacteria possibly erode the mucus layer and contribute to the lethal phenotype of $\mathrm{Cr}$ under fiber deprivation. Removing specific pathogen-promoting and mucus-degrading bacterial species could aid to understand if targeted microbiome modulations could be a tool to prevent severe disease outcomes. Such future studies would also facilitate the understanding whether the changes observed here (mucus reduction, changes in microbial metabolites, and elevated inflammation) independently contribute to the lethal phenotype of $\mathrm{Cr}$ or whether a combination of such changes is essential in order to drive susceptibility to $C r$.

Although the burden of intestinal pathogenic infections is increased and is often more lethal in developing countries compared to westernized countries, ${ }^{56}$ further studies elaborating the connection between a WSD and enteric infections could help to prevent associated diseases such as irritable bowel syndrome ${ }^{57}$ and tackle emerging antibiotic overuse. ${ }^{58}$ Our findings underline the importance of increased dietary fiber consumption in WSD in order to strengthen colonization resistance and barrier integrity within the host against possible enteric infections by EPEC and EHEC.

\section{Acknowledgments}

Work in the authors' laboratory was supported by the following grants to M.S.D.: Luxembourg National Research Fund (FNR) CORE grants (C15/BM/10318186 and C18/BM/12585940). M. N. and A.P. and were supported by the FNR AFR bilateral grant (15/11228353) and FNR AFR individual grant (11602973), respectively. E.T.G. was supported by the FNR PRIDE grant (17/11823097) and the Fondation du Pélican de Mie et Pierre Hippert-Faber under the aegis of the Fondation de Luxembourg. D.B. is supported by the FNR-ATTRACT program (A14/BM/ 7632103). E.C.M. was supported by grants from the US National Institutes of Health (DK118024 and DK125445).

\section{Declarations}

\section{Availability of data and materials}

Most of the data generated or analysed during this study are included in this article. Please contact author for data requests.

\section{Disclosure statement}

The authors declare that they have no competing interests. 


\section{ORCID}

Mahesh S. Desai (iD http://orcid.org/0000-0002-9223-2209

\section{Authors' contributions}

Conceptualization, M.N., D.B., E.C.M., and M.S.D.; Experiments, M.N., M.W., S.W., and A.P.; Investigation, M. N., A.S., E.T.G., and M.S.D.; Resources, M.N., S.W., E.T.G, M. W., A.P., A.S., E.C.M., and M.S.D.; Writing - Original Draft, M.N., A.S., and M.S.D; Writing - Review \& Editing, M.N., A. S., E.T.G., A.P., M.W., E.C.M. and M.S.D.; Supervision, M.S. D.; Funding Acquisition, M.S.D.

\section{References}

1. EFSA. Panel on dietetic products n, allergies. scientific opinion on dietary reference values for carbohydrates and dietary fibre. EFSA Journal 2010;8:1462.

2. Makki K, Deehan EC, Walter J, Bäckhed F. The impact of dietary fiber on gut microbiota in host health and disease. Cell Host Microbe. 2018;23(6):705-715. doi:10.1016/j.chom.2018.05.012.

3. Mefferd CC, Bhute SS, Phan JR, Villarama JV, Do DM, Alarcia S, Abel-Santos E, Hedlund BP. A high-fat/highprotein, atkins-type diet exacerbates Clostridioides (Clostridium) difficile infection in mice, whereas a high-carbohydrate diet protects. mSystems. 2020;5(1): e00765-19.

4. Wotzka SY, Kreuzer M, Maier L, Arnoldini M, Nguyen BD, Brachmann AO, Berthold DL, Zünd M, Hausmann A, Bakkeren E, et al. Escherichia coli limits salmonella typhimurium infections after diet shifts and fat-mediated microbiota perturbation in mice. Nature Microbiology. 2019;4(12):2164-2174. doi:10.1038/s41564019-0568-5.

5. Agus A, Denizot J, Thévenot J, Martinez-Medina $M$, Massier S, Sauvanet P, Bernalier-Donadille A, Denis S, Hofman P, Bonnet R, et al. Western diet induces a shift in microbiota composition enhancing susceptibility to adherent-invasive e. coli infection and intestinal inflammation. Scientific Reports. 2016;6(1):19032. doi:10.1038/srep19032.

6. Jacobson A, Lam L, Rajendram M, Tamburini F, Honeycutt J, Pham T, Van Treuren W, Pruss K, Stabler SR, Lugo K, et al. A gut commensal-produced metabolite mediates colonization resistance to salmonella infection. Cell Host \& Microbe. 2018;24(2):296307.e7. doi:10.1016/j.chom.2018.07.002.

7. Lin L, Zhang J. Role of intestinal microbiota and metabolites on gut homeostasis and human diseases. BMC Immunol. 2017;18(1):2. doi:10.1186/s12865016-0187-3.
8. Smith PM, Howitt MR, Panikov N, Michaud M, Gallini CA, Bohlooly YM, Glickman JN, Garrett WS. The microbial metabolites, short-chain fatty acids, regulate colonic treg cell homeostasis. Science. 2013;341 (6145):569-573. doi:10.1126/science.1241165.

9. Buffie CG, Pamer EG. Microbiota-mediated colonization resistance against intestinal pathogens. Nature Reviews Immunology. 2013;13(11):790-801. doi:10.1038/nri3535.

10. Martens EC, Neumann M, Desai MS. Interactions of commensal and pathogenic microorganisms with the intestinal mucosal barrier. Nat Rev Microbiol. 2018;16 (8):457-470. doi:10.1038/s41579-018-0036-x.

11. Mullineaux-Sanders C, Sanchez-Garrido J, Hopkins EGD, Shenoy AR, Barry R, Frankel G. Citrobacter rodentium-host-microbiota interactions: immunity, bioenergetics and metabolism. Nature Reviews Microbiology. 2019;17(11):701-715. doi:10.1038/s41579-019-0252-z.

12. Cao Y, Liu J, Zhu W, Qin N, Ren X, Zhu B, Xia X. Impact of dietary components on enteric infectious disease. Critical Reviews in Food Science and Nutrition 2021:1-26.

13. Desai MS, Seekatz AM, Koropatkin NM, Kamada N, Hickey CA, Wolter M, Pudlo NA, Kitamoto S, Terrapon N, Muller A, et al. A dietary fiber-deprived gut microbiota degrades the colonic mucus barrier and enhances pathogen susceptibility. Cell. 2016;167 (5):1339-53 e21. doi:10.1016/j.cell.2016.10.043.

14. Erben U, Loddenkemper C, Doerfel K, Spieckermann S, Haller D, Heimesaat MM, Zeitz M, Siegmund B, Kühl AA. A guide to histomorphological evaluation of intestinal inflammation in mouse models. International Journal of Clinical and Experimental Pathology. 2014;7:4557-4576.

15. Greenhalgh K, Ramiro-Garcia J, Heinken A, Ullmann P, Bintener T, Pacheco MP, Baginska J, Shah P, Frachet A, Halder R, et al. Integrated in vitro and in silico modeling delineates the molecular effects of a synbiotic regimen on colorectal-cancer-derived cells. Cell Rep. 2019;27(5):1621-1632.e9. doi:10.1016/j. celrep.2019.04.001.

16. Steimle A, Grant ET, Desai MS. Quantitative assay to detect bacterial glycan-degrading enzyme activities in mouse and human fecal samples. STAR Protocols. 2021;2(1):100326. doi:10.1016/j.xpro.2021.100326.

17. Kozich JJ, Westcott SL, Baxter NT, Highlander SK, Schloss PD. Development of a dual-index sequencing strategy and curation pipeline for analyzing amplicon sequence data on the Miseq illumina sequencing platform. Applied and Environmental Microbiology. 2013;79(17):5112-5120. doi:10.1128/AEM.01043-13.

18. Schloss PD, Westcott SL, Ryabin T, Hall JR, Hartmann M, Hollister EB, Lesniewski RA, Oakley BB, Parks DH, Robinson CJ, et al. Introducing mothur: open-source, 
platform-independent, community-supported software for describing and comparing microbial communities. Applied and Environmental Microbiology. 2009;75 (23):7537-7541. doi:10.1128/AEM.01541-09.

19. Schloss PD, MiSeq SOP 2019; https://mothur.org/wiki/ miseq_sop/ 23.10.2019 Accessed 26 Jul. 2021.

20. Holmes I, Harris K, Quince C, Gilbert JA. Dirichlet multinomial mixtures: generative models for microbial metagenomics. PLOS ONE. 2012;7(2):e30126. doi:10.1371/journal.pone.0030126.

21. Quast C, Pruesse E, Yilmaz P, Gerken J, Schweer T, Yarza P, Peplies J, Glöckner FO. The SILVA ribosomal RNA gene database project: improved data processing and web-based tools. Nucleic Acids Research. 2013;41 (D1):D590-6. doi:10.1093/nar/gks1219.

22. McMurdie PJ, Holmes S, Watson M. phyloseq: an $\mathrm{R}$ package for reproducible interactive analysis and graphics of microbiome census data. PLOS ONE. 2013;8 (4):e61217. doi:10.1371/journal.pone.0061217.

23. Wickham H. ggplot2: elegant graphics for data analysis. Springer-Verlag New York: New York; 2016.

24. Oksanen J, Blanchet FG, Friendly M, Kindt R, Legendre P, McGlinn D, et al. vegan: community ecology package. R package version 2.5-7. 2020; https:// CRAN.R-project.org/package=vegan 26 Jul .2021.

25. Wickham $\mathrm{H}$ forcats: tools for working with categorical variables (Factors). R package version 0.5.1. 2021; https:/CRAN.R-project.org/package=forcats 26 Jul .2021

26. Love MI, Huber W, Anders S. Moderated estimation of fold change and dispersion for RNA-seq data with DESeq2. Genome Biology. 2014;15(12):550. doi:10.1186/s13059-014-0550-8.

27. Anderson MJ, Walsh DCI. PERMANOVA, ANOSIM, and the mantel test in the face of heterogeneous dispersions: what null hypothesis are you testing? Ecological Monographs. 2013;83(4):557-574. doi:10.1890/122010.1.

28. Litvak Y, Byndloss MX, Tsolis RM, Bäumler AJ. Dysbiotic proteobacteria expansion: a microbial signature of epithelial dysfunction. Current Opinion in Microbiology. 2017;39:1-6. doi:10.1016/j. mib.2017.07.003.

29. Ahn J, Sinha R, Pei Z, Dominianni C, Wu J, Shi J, Goedert JJ, Hayes RB, Yang L. Human gut microbiome and risk for colorectal cancer. JNCI: Journal of the National Cancer Institute. 2013;105(24):1907-1911. doi:10.1093/jnci/djt300.

30. Wlodarska M, Willing B, Bravo D, Finlay B. Phytonutrient diet supplementation promotes beneficial Clostridia species and intestinal mucus secretion resulting in protection against enteric infection. Scientific Reports. 2015;5(1):9253. doi:10.1038/ srep09253.
31. BP W, Vacharaksa A, Croxen M, Thanachayanont T, Finlay BB, Bereswill S. Altering host resistance to infections through microbial transplantation. PLOS ONE. 2011;6(10):e26988. doi:10.1371/journal. pone.0026988.

32. Chassaing B, Koren O, Carvalho FA, Ley RE, Gewirtz AT. AIEC pathobiont instigates chronic colitis in susceptible hosts by altering microbiota composition. Gut. 2014;63(7):1069-1080. doi:10.1136/gutjnl-2013304909.

33. Aguirre M, Eck A, Koenen ME, Savelkoul PH, Budding AE, Venema K. Diet drives quick changes in the metabolic activity and composition of human gut microbiota in a validated in vitro gut model. Research in Microbiology. 2016;167(2):114-125. doi:10.1016/j. resmic.2015.09.006.

34. Kortman GAM, Dutilh BE, Maathuis AJH, Engelke UF, Boekhorst J, Keegan KP, Nielsen FGG, Betley J, Weir JC, Kingsbury Z, et al. Microbial metabolism shifts towards an adverse profile with supplementary iron in the TIM-2 in vitro model of the human colon. Frontiers in Microbiology. 2016;6:1481. doi:10.3389/fmicb.2015.01481.

35. El Kaoutari A, Armougom F, Gordon JI, Raoult D, Henrissat B. The abundance and variety of carbohydrate-active enzymes in the human gut microbiota. Nat Rev Microbiol. 2013;11(7):497-504. doi:10.1038/nrmicro3050.

36. NE D, Willing BP. Microbial fermentation of dietary protein: an important factor in $\operatorname{diet} \square$ microbe $\square$ host interaction. Microorganisms. 2019;7.

37. Yao CK, Muir JG, Gibson PR. Review article: insights into colonic protein fermentation, its modulation and potential health implications. Alimentary Pharmacology \& Therapeutics. 2016;43(2):181-196. doi:10.1111/apt.13456.

38. Hughes R, Kurth MJ, McGilligan V, McGlynn H, Rowland I. Effect of colonic bacterial metabolites on Caco-2 cell paracellular permeability in vitro. Nutr Cancer. 2008;60(2):259-266. doi:10.1080/ 01635580701649644

39. Burger-van Paassen N, Vincent A, Puiman PJ, van der Sluis M, Bouma J, Boehm G, van Goudoever J, van Seuningen I, Renes I. The regulation of intestinal mucin MUC2 expression by short-chain fatty acids: implications for epithelial protection. Biochem J. 2009;420(2):211-219. doi:10.1042/BJ20082222.

40. Peng L, Li Z-R, Green RS, Holzman IR, Lin J. Butyrate enhances the intestinal barrier by facilitating tight junction assembly via activation of AMP-activated protein kinase in Caco-2 cell monolayers. J Nutr. 2009;139 (9):1619-1625. doi:10.3945/jn.109.104638.

41. Zhao Y, Chen F, Wu W, Sun M, Bilotta AJ, Yao S, Xiao Y, Huang X, Eaves-Pyles TD, Golovko G, et al. GPR43 mediates microbiota metabolite SCFA 
regulation of antimicrobial peptide expression in intestinal epithelial cells via activation of mTOR and STAT3. Mucosal Immunology. 2018;11(3):752-762. doi:10.1038/mi.2017.118.

42. Osbelt L, Thiemann S, Smit N, Lesker TR, Schröter M, EJC G, Schmidt-Hohagen K, Pils MC, Mühlen S, Dersch P, et al. Variations in microbiota composition of laboratory mice influence Citrobacter rodentium infection via variable short-chain fatty acid production. PLOS Pathogens. 2020;16(3):e1008448. doi:10.1371/journal.ppat.1008448.

43. Yang W, Yu T, Huang X, Bilotta AJ, Xu L, Lu Y, Sun J, Pan F, Zhou J, Zhang $\mathrm{W}$, et al. Intestinal microbiota-derived short-chain fatty acids regulation of immune cell IL-22 production and gut immunity. Nature Communications. 2020;11(1):4457. doi:10.1038/s41467-020-18262-6.

44. Bomar L, Maltz M, Colston S, Graf J, Handelsman J. Directed culturing of microorganisms using metatranscriptomics. mBio. 2011;2(2):e00012-11. doi:10.1128/mBio.00012-11.

45. Pereira FC, Wasmund K, Cobankovic I, Jehmlich N, Herbold CW, Lee KS, Sziranyi B, Vesely C, Decker T, Stocker R, et al. Rational design of a microbial consortium of mucosal sugar utilizers reduces Clostridiodes difficile colonization. Nature Communications. 2020;11(1):5104. doi:10.1038/s41467-020-18928-1.

46. Bell A, Brunt J, Crost E, Vaux L, Nepravishta R, Owen CD, Latousakis D, Xiao A, Li W, Chen X, et al. Elucidation of a sialic acid metabolism pathway in mucus-foraging Ruminococcus gnavus unravels mechanisms of bacterial adaptation to the gut. Nat Microbiol. 2019;4(12):2393-2404. doi:10.1038/s41564019-0590-7.

47. Crost EH, Tailford LE, Monestier M, Swarbreck D, Henrissat B, Crossman LC, et al. The mucin-degradation strategy of Ruminococcus gnavus: the importance of intramolecular trans-sialidases. Gut Microbes. 2016;7:302-312. doi:10.1080/ 19490976.2016.1186334.

48. Kamada N, Kim YG, Sham HP, Vallance BA, Puente JL, Martens EC, Nunez G. Regulated virulence controls the ability of a pathogen to compete with the gut microbiota. Science. 2012;336(6086):1325-1329. doi:10.1126/science.1222195.

49. Fabich AJ, Jones SA, Chowdhury FZ, Cernosek A, Anderson A, Smalley D, McHargue JW, Hightower GA, Smith JT, Autieri SM, et al. Comparison of carbon nutrition for pathogenic and commensal escherichia coli strains in the mouse intestine. Infect Immun. 2008;76(3):1143-1152. doi:10.1128/IAI.01386-07.

50. Bergstrom KS, Kissoon-Singh V, Gibson DL, Ma C, Montero M, Sham HP, Ryz N, Huang T, Velcich A, Finlay BB, et al. Muc2 protects against lethal infectious colitis by disassociating pathogenic and commensal bacteria from the colonic mucosa. PLoS Pathog. 2010;6(5):e1000902. doi:10.1371/journal.ppat.1000902.

51. Dann SM, Le C, Choudhury BK, Liu H, Saldarriaga O, Hanson EM, Cong Y, Eckmann L. Attenuation of intestinal inflammation in interleukin-10-deficient mice infected with Citrobacter rodentium. Infect Immun. 2014;82(5):1949-1958. doi:10.1128/IAI.00066-14.

52. Zheng Y, Valdez PA, Danilenko DM, Hu Y, Sa SM, Gong Q, Abbas AR, Modrusan Z, Ghilardi N, de Sauvage FJ, et al. Interleukin-22 mediates early host defense against attaching and effacing bacterial pathogens. Nat Med. 2008;14(3):282-289. doi:10.1038/nm1720.

53. An J, Zhao X, Wang Y, Noriega J, Gewirtz AT, Zou J, Baumler AJ. Western-style diet impedes colonization and clearance of Citrobacter rodentium. PLoS Pathog. 2021;17(4):e1009497. doi:10.1371/journal.ppat.1009497.

54. Gasaly N, Hermoso MA, Gotteland M. Butyrate and the fine-tuning of colonic homeostasis: implication for inflammatory bowel diseases. International Journal of Molecular Sciences. 2021;22(6):3061. doi:10.3390/ijms22063061.

55. Donohoe DR, Garge N, Zhang X, Sun W, O'Connell TM, Bunger MK, Bultman S. The microbiome and butyrate regulate energy metabolism and autophagy in the mammalian colon. Cell Metab. 2011;13(5):517-526. doi:10.1016/j. cmet.2011.02.018.

56. Fletcher SM, McLaws ML, Ellis JT. Prevalence of gastrointestinal pathogens in developed and developing countries: systematic review and meta-analysis. Journal of Public Health Research. 2013;2(1):42-53. doi:10.4081/ jphr.2013.e9.

57. Card T, Enck P, Barbara G, Boeckxstaens GE, Santos J, Azpiroz F, Mearin F, Aziz Q, Marshall J, Spiller R, et al. Post-infectious IBS: defining its clinical features and prognosis using an internet-based survey. United European Gastroenterology Journal. 2018;6 (8):1245-1253. doi:10.1177/2050640618779923.

58. Aslam B, Wang W, Arshad MI, Khurshid M, Muzammil S, Rasool MH, Nisar MA, Alvi RF, Aslam MA, Qamar MU, et al. Antibiotic resistance: a rundown of a global crisis. Infection and Drug Resistance. 2018;11:1645-1658. doi:10.2147/IDR.S173867. 